\title{
Measurement of ecological niche of Quercus aliena and Q. serrata under environmental factors treatments and its meaning to ecological distribution
}

\author{
Seung-Hyuk Lee and Young-Han You* \\ Department of Biology, Kongju National University, Gongju 314-701, Korea
}

\begin{abstract}
Quercus aliena and Q. serrata are both occur as natural vegetation alongside natural freshwater bodies of the southern Korea Peninsula. Q. serrata dominates over Q. aliena as secondary forest vegetation in the present day. In order to explain these natural distributional traits of the oak species, we conducted some experiments with oak seedlings which treated with major important environmental resources, including light, moisture and nutrients, under controlled conditions. We then measured the ecological niche breadths and overlap from 15 eco-morphological characteristics. The ecological niche breadth of Q. aliena and Q. serrata were higher in terms of the nutrient factor applied, but was lower terms of light. The niche breadth of Q. serrata was wider than that of Q. aliena in light and moisture exposure. On the other hand, the niche breadth of $Q$. aliena was similar with that of $Q$. serrata in terms of the nutrient factor applied. These results imply that $Q$. serrata has a broader ecological distribution in over a wider variety of light and moisture environments than that of Q. alien. Ecological niche overlap between two oak species was the widest in terms of the light treatment factor applied, and narrowest in terms of moisture. This response pattern was also verified by cluster and principle component analysis. These results suggest competitive interactions between Q. serrata and Q. aliena seedlings may be higher for light resources than moisture or nutrient resources, and that Q. serrata is more shade tolerant than Q. aliena.
\end{abstract}

Key words: distribution, environmental factor, multivariate analysis, niche breadth, niche overlap

\section{INTRODUCTION}

Ecological niche had been introduced by Grinnell (1917) who interpreted it as the ultimate distributional unit of a species in a spatial sense. Later, the ecological niche was used explaining the niche functional aspects when describing an organism's place in its biotic environment in connection with its nutrition (Elton 1927). Hutchinson (1957) reported that niche is the sum of all the environmental factors acting on the organism, a region of an n-dimensional hypervolume. Ecological niche was also defined as the functional role or status of the organism within its community and ecosystem resulting from the organism's structural adaptations, physiological responses, and specific behavior (Odum 1969).

Ecological niche has been divided into two categories, ecological niche breadth and ecological niche overlap. The niche breadth of a given species and for a given parameter is the range of environmental tolerance between the maximum and minimum of that parameter, under which the species may survive. It is the scope of tolerance and is dependent on the response of a species to

\section{Open Access http://dx.doi.org/10.5141/JEFB.2012.027}

This is an Open Access article distributed under the terms of the Creative Commons Attribution Non-Commercial License (http://creativecommons. org/licenses/by-nc/3.0/) which permits unrestricted non-commercial use distribution, and reproduction in any medium, provided the original work is properly cited.
Received 13 June 2012, Accepted 04 July 2012

*Corresponding Author

E-mail: youeco21@kongju.ac.kr

Tel: +82-41-850-8508 
the environmental factor which it describes. Species with small niche breadths refer to species with narrower distributions within nature, and smaller sizes of populations. whereas an organism with a larger niche breadth refers to its wider range in nature and larger size of populations owing to its adaptability to changing environments (Pianka 1983).

Ecological niche overlap means a similar response to an environmental factor or the utilization of the same natural resource by two or more species, and because competition intensity increases with higher niche overlap (Schoener 1970, Hanski 1978, Hulbert 1978, Yimin et al. 2006), intra- or interspecific competitions can be estimated and compared by ecological niche overlap (Abrams 1980).

In Korea, deciduous oak species dominate in the south and central regions (Kim et al. 1981). Q. serrata is widespread in lowlands of the central region and the entire region of south (Chung and Lee 1965). Q. serrata is distributed in an optimum: warmth index of $67-92^{\circ} \mathrm{C} \cdot$ month; geographic location of $35^{\circ} 00$ to $36^{\circ} 30 \mathrm{~N}$; and altitude of $317 \mathrm{~m}$ above sea level (Yim and Baek 1985, Yang 2001). Q. serrata is recognized as a climax species of forest succession in the south region of Korea (Park 1984, Kim and Kil 2000, Sim and Han 2003, Lee 2007, Song 2007). Q. serrata is mainly distributed in the south and is described as dominant tree species in cool temperate forests (Kim and Lee 2006).

Q. aliena occurs within Korean forests, in the optimum: warmth index of $67-98^{\circ} \mathrm{C} \cdot$ month: with geographic location of $35^{\circ} 00$ to $37^{\circ} 70 \mathrm{~N}$; and altitude of $298 \mathrm{~m}$ above sea level (Yim and Baek 1985, Yang 2001). Contrary to Q. serrata which is usually the dominant overstory layer, Q. alie$n a$ composes the understory vegetation of secondary forests in the lowlands of the Korean Peninsula (Song 2007). This species is also an important relict vegetation of older forests and culturally important sites, such as Changdeok Palace, Secret Garden and Gongsanseong Fortress in Korea (Oh and Lee 1986) and is an instantly recognizable facet of Korean heritage.

However, Q. serrata and Q. aliena in Kwangnung Experimental Forest appeared together as a dominant species (You et al. 1995). They have been reported as potentially being the natural climax state of riverside vegetation within Korea (Kim et al. 2008a), and the edaphic climax species in moist lowland forests (Lee 2007, Song 2007). Also, Kim and Kim (1994) determined that Q. aliena was better able to adapt itself to moist conditions than other deciduous species. In contrast, Han et al. (2009) later reported that Q. serrata grew better than Q. aliena under conditions of flooding.

Over the past few years, only several studies based upon manipulative experiments for these two species' ecological traits. Thus, in order to understand the ecological difference and similarity between these two oak species in the natural forest, it is essential to examine each of their ecological niches, based on experimental data obtained from several controlled environment treatments (Grime et al. 1998). Linking the observed distributions of species in their native ranges to ecological niches offers a framework for predicting species distributions (Albright et al. 2010). The object of this study is to clarify these ecological characteristics in order to explain the distribution of these two oak species. Thus, we conducted growth analysis and measured ecological niche breadth and overlap between Q. serrata and Q. aliena in terms of the major environmental resources for early seedling growth.

\section{METERIALS AND METHODS}

\section{Collecting seeds of two oak species}

The seeds of both oak species were collected from the foot of a mountain at Shingwan-dong, Gongju-city, Chungnam Province, with a geographic location of $127^{\circ} 07^{\prime} \mathrm{E}$ to $36^{\circ} 27^{\prime} \mathrm{N}$, and an altitude of $27 \mathrm{~m}$ above sea level in October of 2009. The seeds were sorted according to similarity of size, and were then stored at $4^{\circ} \mathrm{C}$ for approximately 6 months, until they were sown prior to the initiation of the experiment. Two acorns of each species were sown in each of 48 pots (diameter $23.5 \mathrm{~cm}$, height $24 \mathrm{~cm}$ ) filled with sterilized river bed sand in April, 2010, and the acorns germinated after 2-3 weeks.

\section{Gradients of environmental factor}

Three environmental factors, light, moisture and nutrient, were known to usually be the most important agents influencing the distribution of plants (Barbour et al. 1987). The seedlings of each species were treated with these three environmental factors, each consisting of 4 gradients. There were four replications of each treatment for each species, giving a total of 8 seedlings applied to each treatment, and an overall total of 96 seedlings.

The four gradients of the light factor treatment were as follows: L4 (high light) ( $100 \%$ of full light within the greenhouse, $787.75 \pm 77.76 \mu \mathrm{mol} \mathrm{m}^{-2} \mathrm{~s}^{-1}$ ), L3 (medium high) (50\% of full light, $389 \pm 45.66 \mu \mathrm{mol} \mathrm{m}{ }^{-2} \mathrm{~s}^{-1}$ ), L2 (medium low) ( $30 \%$ of full light, $\left.156.2 \pm 29.15 \mu \mathrm{mol} \mathrm{m}^{-2} \mathrm{~s}^{-1}\right), \mathrm{Ll}$ (low 
light) ( $10 \%$ of full light, $\left.76.8 \pm 2.16 \mu \mathrm{mol} \mathrm{m}^{-2} \mathrm{~s}^{-1}\right)$. Light was controlled by varying the number of layers of shade cloth surrounding each treatment. Light intensity was determined with a portable LI-COR (Model 250A; Li-Cor, Lincoln, NE, USA) light meter once a day, and average values were calculated.

The four gradients of the water factor treatment were categorized as M4-M1 (mL water/plant), which was provided to the plants every 3-4 days: M4 (700 mL), M3 (500 $\mathrm{mL}), \mathrm{M} 2(300 \mathrm{~mL}), \mathrm{M} 1(100 \mathrm{~mL})$. The reference volume of water was determined by calculating moisture carrying capacity $(700 \mathrm{~mL})$ of a pot, and the remaining gradients (M3-M1) were determined by reducing the volume of each by $200 \mathrm{~mL}$, so as to cover a range of moisture conditions.

The nutrient treatment was also classified into four levels: $\mathrm{N} 4$ (15\%: $\left.127.5 \mathrm{mg} \mathrm{NH}_{4}{ }^{+}-\mathrm{N}, 82.5 \mathrm{mg} \mathrm{NO}_{3}{ }^{-} \mathrm{N}\right)$, $\mathrm{N} 3(10 \%$ : $\left.85 \mathrm{mg} \mathrm{NH}_{4}{ }^{+} \mathrm{N}, 55 \mathrm{mg} \mathrm{NO}_{3}{ }^{-} \mathrm{N}\right)$, N2 (5\%: 42.5mg NH${ }_{4}{ }^{+} \mathrm{N}$, $\left.27.5 \mathrm{mg} \mathrm{NO}_{3}-\mathrm{N}\right), \mathrm{N} 1(0 \%$ : none). Potting media in the nutrient experiment were fortified once only at the start of the experiment at rates of $15 \%, 10 \%, 5 \%$ and $0 \%$ fertilizer which containing an ammonium nitrogen content of below $170 \mathrm{mg} / \mathrm{L}$, and nitrate nitrogen at a concentration of $110 \mathrm{mg} / \mathrm{L}$ (Bio-Best bed soil, Seminis) per $1 \mathrm{~kg}$ of sand.

\section{Cultivation and measurements}

The seedlings of Q. serrata and Q. aliena were cultivated in the glasshouse of Kongju National University from May to October 2010. Harvested seedlings were dissected and separated into shoots, roots and leaves of them with washing root part of the seedlings. We measured the petiole length, the stem length, the shoot length and the root length with a ruler in centimeter levels (cm). We also weighed the leaf weight, the petiole weight, the lamina weight, the stem weight, the shoot weight, root weight and total weight $(\mathrm{g})$. The lamina length $(\mathrm{cm})$, the leaf width $(\mathrm{cm})$ were measured with a SKYE model SI700 plant analysis systems (SKYE, Wales, UK) and the leaf area $\left(\mathrm{cm}^{2}\right)$ were analyzed by leaf area v1.11 (Skye, 2007). Stem diameter $(\mathrm{cm})$ was measured slightly above the root collar by using digital calipers (Mitutoyo, Kawasaki, Japan). All parts of the plants were dried at $70^{\circ} \mathrm{C}$ for $48 \mathrm{~h}$ before weighing.

\section{Ecological niche breadth and ecological niche overlap}

The proportional response of plants for each treatment, and along each gradient was calculated as a pro- portion of the sum of responses over all states (e.g., the total leaf area of each treatment was expressed as a proportion of the total leaf area for that species as the sum of all four treatments). Niche breadths were calculated for each treatment and gradient combination as follows (Levins 1968):

$$
\begin{aligned}
& \mathrm{B}=1 / \sum\left(\mathrm{P}^{2}\right) \mathrm{S} \\
& \mathrm{B}: \text { niche breadth (Levins' } \mathrm{B}) \\
& \mathrm{P} i \text { : relative response of a given species to the whole } \\
& \text { gradients that is realized in gradient } i \\
& \mathrm{~S} \text { : total number of gradients that is all treatments }
\end{aligned}
$$

Niche overlap, the equivalency of responses between two oak species was assessed by proportional similarity between pairs of two oak species. Proportional similarity (Schoener 1970) was calculated as:

$$
\begin{aligned}
& \mathrm{PS}=1-1 / 2 \sum|\mathrm{P} i j-\mathrm{P} i h| \\
& \mathrm{PS}=\text { proportional similarity (niche overlap) } \\
& \mathrm{P} i j=\text { relative response of species } j \text { in the } i \text { the gradient } \\
& \mathrm{P} i h=\text { relative response of species } h \text { in the } j \text { the gradient }
\end{aligned}
$$

\section{Statistical analysis}

We conducted cluster analysis and principal component analysis by STATISTICA 7 (Statsoft, Inc., Tulsa, OK, USA) in order to clarify overall tendency of growth responses of both species according to environmental resource factors. The cluster analysis was used in terms of unweighted pair-group average, following estimated Euclidean distance, and principle component analysis (PCA) used spearman's correlation value of measured variables (Noh and Jeong 2002).

\section{RESULTS}

\section{Ecological niche breadth}

In niche breadth of $Q$. aliena, the characters related with leaf area, lamina length, leaf width length, petiole length, stem length, shoot length, stem diameter, root length, stem weight and shoot weight were high in the range of 0.931-1.000 in the three environmental resource treatments (Table 1). However, niche breadth of lamina weight, petiole weight, leaf weight, root weight and total weight was varied along the environmental factors; nutrient (0.958-0.993) was wider than moisture (0.691-0.985) or light (0.529-0.939). Over all, the niche breadth of Q. ali- 
ena decreased in the order of nutrient (0.985), moisture (0.958) and light (0.913).

In niche breadth of Q. serrata, the characters such as leaf area, lamina length, leaf width length, petiole length, stem length, shoot length, stem diameter, root length, lamina weight, stem weight and shoot weight, were high in the range of 0.915-0.999 in all the environmental resource

Table 1. Niche breadth of Quercus aliena along each environmental factor

\begin{tabular}{lccc}
\hline Items & Light & Moisture & Nutrient \\
\hline Leaf area & 0.995 & 0.992 & 0.975 \\
Lamina length & 0.996 & 0.996 & 0.995 \\
Leaf width length & 0.998 & 1.000 & 0.992 \\
Petiole length & 0.965 & 0.982 & 0.994 \\
Stem length & 0.968 & 0.999 & 0.987 \\
Shoot length & 0.981 & 1.000 & 0.997 \\
Stem diameter & 0.971 & 0.947 & 0.984 \\
Root length & 0.984 & 0.989 & 0.989 \\
Lamina weight & 0.927 & 0.887 & 0.983 \\
Petiole weight & 0.939 & 0.691 & 0.993 \\
Leaf weight & 0.877 & 0.985 & 0.992 \\
Stem weight & 0.950 & 0.984 & 0.980 \\
Shoot weight & 0.931 & 0.990 & 0.991 \\
Root weight & 0.529 & 0.965 & 0.958 \\
Total weight & 0.681 & 0.971 & 0.970 \\
Mean \pm SD & $0.913 \pm 0.132$ & $0.958 \pm 0.079$ & $0.985 \pm 0.01$ \\
\hline
\end{tabular}

Table 2. Niche breadth of Quercus serrata along each environmental factor

\begin{tabular}{lccc}
\hline Items & Light & Moisture & Nutrient \\
\hline Leaf area & 0.996 & 0.986 & 0.986 \\
Lamina length & 0.999 & 0.998 & 0.998 \\
Leaf width length & 0.999 & 0.994 & 0.992 \\
Petiole length & 0.985 & 0.990 & 0.985 \\
Stem length & 0.982 & 0.994 & 0.994 \\
Shoot length & 0.976 & 0.991 & 0.991 \\
Stem diameter & 0.955 & 0.993 & 0.968 \\
Root length & 0.989 & 0.995 & 0.993 \\
Lamina weight & 0.920 & 0.939 & 0.993 \\
Petiole weight & 0.997 & 0.745 & 0.998 \\
Leaf weight & 0.888 & 0.938 & 0.932 \\
Stem weight & 0.927 & 0.965 & 0.996 \\
Shoot weight & 0.915 & 0.967 & 0.973 \\
Root weight & 0.651 & 0.973 & 0.972 \\
Total weight & 0.710 & 0.974 & 0.975 \\
Mean \pm SD & $0.926 \pm 0.106$ & $0.963 \pm 0.063$ & $0.983 \pm 0.017$ \\
\hline
\end{tabular}

treatments (Table 2). But, niche breadth of petiole weight, leaf weight, root weight and total weight was varied; nutrient (0.932-0.998) was wider than moisture (0.745-0.974) or light (0.651-0.997). Average niche breadth of Q. serrata decreased according to nutrient (0.983), moisture (0.963) and light (0.926). As a result, light is the most important treatment because of narrower niche breadth and difference of niche breadth value between two oak species in light.

\section{Ecological niche overlap}

Ecological niche overlap between Q. aliena and Q. serrata was 0.948 for light, 0.927 for nutrient resources and 0.921 for moisture (Table 3). For light treatment, with the exception of petiole length (0.897), overlap of all characters was high $0.900-0.986$. For light gradients, ecological niche overlap between two oaks was highest in the range of 0.897-0.986 among three environmental resources determined, indicating that the majority of inter-competition between the two species is based on light resources.

For nutrient treatment, leaf area (0.894) and leaf weight (0.875) were relatively narrower, while the others were relatively wider (0.904-0.973). Lamina, petiole and total weight and stem diameter were shown to have a somewhat narrower overlap (0.826-0.897) between two oak species where moisture treatment. On the other hand, the rest of the characters showed a wider overlap (0.091-

Table 3. Niche overlap between Quercus aliena and Q. serrata along each environmental factor

\begin{tabular}{lccc}
\hline Items & Light & Moisture & Nutrient \\
\hline Leaf area & 0.975 & 0.960 & 0.894 \\
Lamina length & 0.985 & 0.952 & 0.958 \\
Leaf width length & 0.983 & 0.962 & 0.933 \\
Petiole length & 0.897 & 0.964 & 0.926 \\
Stem length & 0.953 & 0.947 & 0.973 \\
Shoot length & 0.930 & 0.944 & 0.943 \\
Stem diameter & 0.967 & 0.880 & 0.942 \\
Root length & 0.962 & 0.963 & 0.924 \\
Lamina weight & 0.986 & 0.881 & 0.916 \\
Petiole weight & 0.902 & 0.826 & 0.964 \\
Leaf weight & 0.940 & 0.897 & 0.875 \\
Stem weight & 0.900 & 0.936 & 0.922 \\
Shoot weight & 0.971 & 0.918 & 0.904 \\
Root weight & 0.903 & 0.901 & 0.905 \\
Total weight & 0.970 & 0.888 & 0.919 \\
Mean \pm SD & $0.948 \pm 0.034$ & $0.921 \pm 0.041$ & $0.927 \pm 0.027$ \\
\hline
\end{tabular}


0.964) (Table 3). These results mean that two oak species have also broader resource utilization in nutrient and moisture, but the extent of competition is less than light.

\section{Cluster analysis}

The environmental responses of two oak species was discriminated into two groups (Fig. 1). All the moisture and nutrient treatments, and light 3 level and 4 level of two species were clustered together in group I. Within

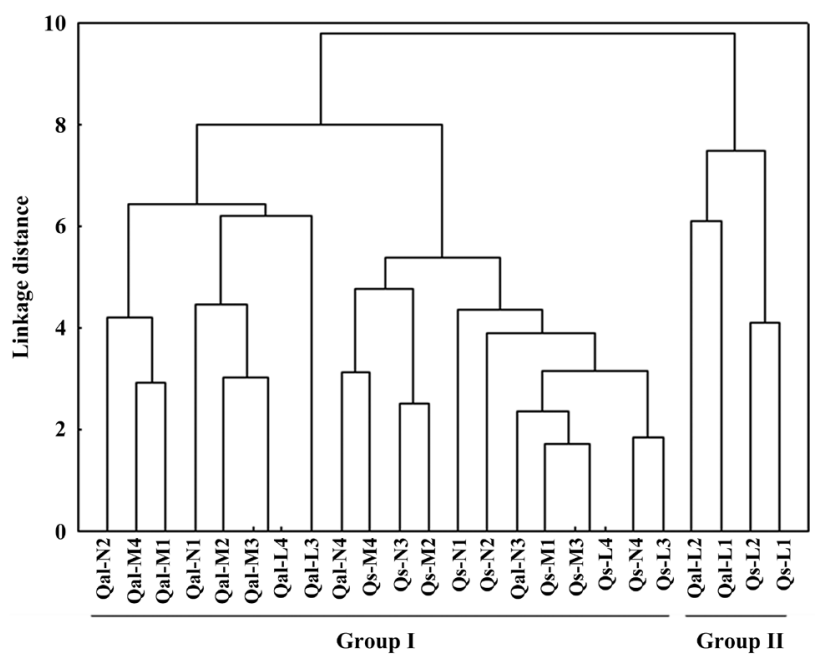

Fig. 1. Unweighted pair-group average clustering of two species treated with three environmental factors ( $L$, light treatment; $M$, moisture; $\mathrm{N}$, nutrient). Numerals within plot indicate treatment gradients in each environmental factor. Qal, Quercus aliena; Qs, Q. serrata.

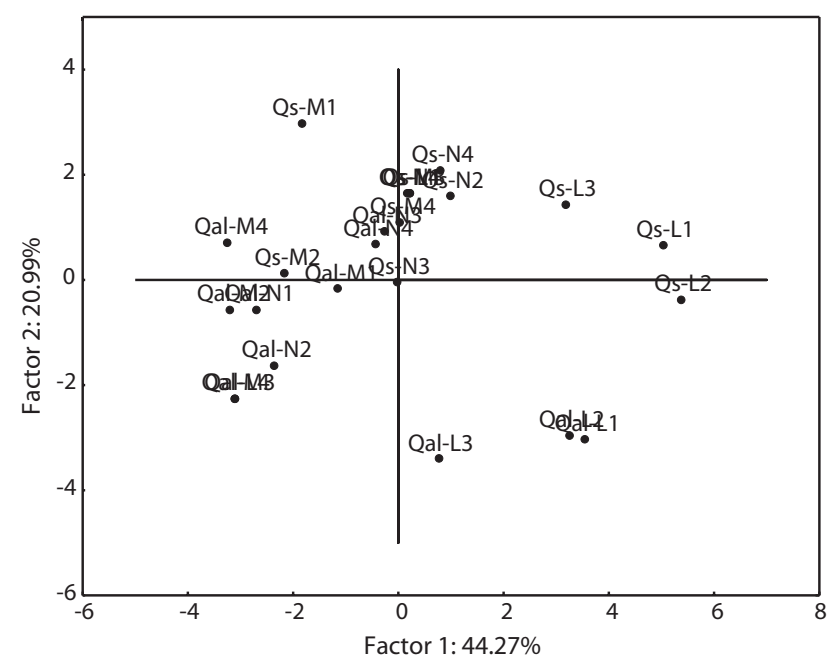

Fig. 2. Principle component analysis ordination of 24 individuals of Quercus aliena (Qal) and Q. serrata (Qs) using 15 variables treated with three environment factors ( $L$, light treatment; $M$, moisture; $N$, nutrient). Numerals within plot indicate treatment gradients in each environmental factor. group I, the individual oaks were again divided into two sub groups: sub-group 1 (Qal-N2 to Qal-L3), sub-group 2 (Qal-N4 to Qs-L3). Qal-N4 and -N3 belonged to group of Q. serrata (Qs). Group II consisted of the lower light conditions light 1 (L1) and 2 (L2) of both species. The response of the two oak species was the same to moisture level 3 (M3) and light level 4 (L4).

\section{Principal component analysis}

PCA was carried out on 15 eco-morphological variables (Fig. 2). Individuals of Q. aliena and Q. serrata were plotted in the space defined by first two factor axes. Approximately, two oak species were discriminatively arranged up (Qs, Q. serrata) and down (Qal, Q. aliena) based on transversal line. Also, the configuration plot showed that nutrient $(-\mathrm{N})$ and moisture $(-\mathrm{M})$ requirements of both oak species were very close to each other on the left, but the light treatments (-L), especially lower light intensities (-L1, L2), were far away to the right, indicating that two oaks species have different responses to low light conditions. It is clearly visible that all features (15 variables) relied on axis 1 and axis II are highly correlated with most variables, except root length and petiole weight $(r<0.5)$ (Table 4).

Table 4. Correlation matrix of 15 variables with the first two principal component scores of principle component analysis analysis

\begin{tabular}{lcc}
\hline & \multicolumn{2}{c}{ Factor } \\
\cline { 2 - 3 } Variables & I & II \\
\hline Leaf area & -0.493 & -0.835 \\
Lamina length & -0.491 & -0.799 \\
Leaf width length & -0.284 & -0.862 \\
Petiole length & -0.150 & -0.568 \\
Stem length & 0.734 & -0.381 \\
Shoot length & 0.668 & -0.488 \\
Stem diameter & -0.743 & 0.129 \\
Root length & -0.440 & 0.139 \\
Lamina weight & -0.575 & -0.397 \\
Petiole weight & -0.385 & 0.161 \\
Leaf weight & -0.859 & 0.206 \\
Stem weight & -0.824 & -0.114 \\
Shoot weight & -0.914 & 0.114 \\
Root weight & -0.859 & 0.190 \\
Total weight & -0.924 & 0.203 \\
Variance explained $(\%)$ & 44.27 & 20.99 \\
\hline
\end{tabular}




\section{DISCUSSION}

The response of the two oak species to environmental resources was related with most of the measured characters rather, and more strongly related to a few dominant one. Within the similar habitats plant species display character convergence in terms of their physiology and life history (Cody and Mooney 1978, Walter 1985). Our results of the niche breadth of two oaks species were widest where nutrient treatments were concerned and narrowest where light treatment were concerned. Therefore, where any reasonable nutrient and moisture availability exists and in generally healthy natural conditions, light is the most influential factor for the two oaks species. According to Kim et al. (2008b), niche breadth of Q. acutissima and Q. variabilis were the narrowest for light treatment. When the two species were compared (Tables 1 and 2), the niche breadth of $Q$. serrata was found to be broader than that of Q. aliena in terms of light and moisture resources, while both species were similar to each other in terms of nutrient resources. The broader niche breadth becomes, the more the dominance of a species increases, and similarly, a species with narrow niche breadth has a more restrictive habitat requirement (Paine et al. 1981). The results of this study indicate that $Q$. serrata has a relatively broader ecological distributions in terms of light and moisture resources than does Q. aliena.

In general, most early successional species have a relatively low shade tolerance and a broad ecological niche breadth in terms of light, due to their low light saturation point (Mandaák and Pyšek 2001). Also, the ecological niche breadth of early successional species is wider than that of late successional species (Lee and Bazzaz 1985). According to our study, the niche breadth of $Q$. serrata was broader than that of $Q$. aliena, and the reduction in growth of $Q$. aliena was greater than that of $Q$. serrata under shaded conditions (Ha 1989, Lim et al. 2012). Thus, we can determine that $Q$. serrata is more adapted to shade conditions than Q. aliena.

We found that the ecological niche overlap of the two oak species was broader in terms of light conditions than in terms of water or nutrient availability (Table 3). Thus, competition between $Q$. aliena and $Q$. serrata for light may be strong. Competition should be understood in connection with the niche concept, since some similarity or overlap in niches is a prerequisite of competition, and since niche shifts provide the clearest evidence of competition (Diamond 1978). If species have identical ecological niches, they could not avoid intraspecific and interspecific competition (Abrams 1980). The extent of niche overlap is determined by their respective resource utilization, and the extent of competition is related to the degree of overlap dimension. Each dimension in the niche space represents an environmental variable, potentially or actually important for species persistence. Species have tendencies to narrow their niches due to interspecific competition and intraspecific optimization. Consequently, niche widening often occurs when the species is released from interspecific competition (Polechová and Storch 2008). Therefore intraspecific competition is intense competition due to a broad niche overlap of their equipollency ecological niche. The two oaks species are distributed in the flood plain of natural river systems of South Korea (Kim et al. 2008a). Our result showed broader niche breadth of both species according to soil moisture and nutrient availability, and niche overlap between two species was lowest in terms of soil moisture. There is at least some competition between Q. serrata and Q. aliena though the two species can live together without competition for moisture.

Light is an important factor for early germination and seedling growth (Grime and Jeffrey 1965, Grime 1979, Canham et al. 1990, Gaudio et al. 2011, Jensen et al. 2012). Also, Hong and Nakagoshi (1998) reported that successful germination and sapling growth of oak in early successional stages is determined to a high degree by light conditions. We have discussed that $Q$. serrata is more shade tolerant than Q. aliena. Nonetheless, two oak species may be influenced by light due to the result of this niche overlap. This is somewhat consistent with the other experimental results. Baek and Cho (1996) found that light actually affected the growth of seedlings of $Q$. serrata. In fact, Q. serrata is highly dependent on light resources and is somewhat specialized in its preference for high light condition. Q. aliena showed an increased diameter growth compared to a further 5 deciduous oak species $(Q$. acutissima, Q. aliena, Q. dentata, Q. mongolica, Q. serrata) under $\mathbf{1 0 0 \%}$ and $75 \%$ light treatments (Korea Forest Research Institute 1989). Also, Q. serrata is a representative of heliophilous trees which invade, and eventually replace grasslands in temperate regions of Japan (Yanhong et al. 1994). These results show that the factor of light clearly influenced both species which dominate this region of South Korea.

In terms of the results of cluster analysis, PCA compared well with clustering classification (Fig. 1). As Fig. 2 indicates, individuals of both oak species were found to be spatially overlapped in terms of those factors of axis I (-M and -N, L-1 and L-2) and to a lesser degree by those of axis II. The distinguishing characteristics of two oak spe- 
cies was related with axis II. Nutrient (-N) and moisture (-M) responses of the two oak species were closely located within the left group, and light levels (-L) except high light levels (L-3, L-4) were located on the right (Fig. 2). Based on the PCA, the ecological responses of the two oak species have similar patterns of cluster analysis (ex. Qal-N3, QalN4) in Q. serrata group I, indicating that the two oak species had an analogous response to a high nutrient conditions, and suggesting that two oak species have similar ecological responses to moisture and nutrient resources, but different responses to low light conditions. Lower light conditions of two oaks species respectively located up (Qs, L-1 and -2) and down (Qal, L-1 and -2) based on transversal line. These results determined that the spatial overlapping of the two oak species differ significantly from other deciduous oak species (Kim et al. 2008a, Lee and You 2009). The indices of niche breadth and niche overlap can be used to reflect the ecological specialization of the species within their particular environments, as well as the potential for competition with co-occurring organisms (Levins 1968). It was inferred from these data that both oak species entail the classical way to avoid or minimize competition in varying light conditions, through the differentiation of their specific light requirements.

The results of Table 4 validate the above results. The most correlation values with measured features $(r<0.5)$ means that the selected 15 variables were involved in ecological responses of both two oak species. These observations suggest that the configuration of the PCA of 24 individuals of $Q$. aliena and $Q$. serrata can be achieved either with factor I and factor II (Table 4).

Finally, both oak species have narrower ecological niche breadths and a wide ecological niche overlap in relation to light resources, and the response pattern of the two oak species to the light factor was more pronounced than that for moisture or nutrient factors. These results mean that two oak species are clearly more influenced by light resources than water or nutrient resources.

\section{ACKNOWLEDGMENTS}

This study was supported by National Research Foundation of Korea (grant No. 2010-0006494).

\section{LITERATURE CITED}

Abrams P. 1980. Some comments on measuring niche overlap. Ecology 61: 44-49.
Albright TP, Chen H, Chen L, Guo Q. 2010. The ecological niche and reciprocal prediction of the disjunct distribution of an invasive species: the example of Ailanthus altissima. Biol Invasions 12: 2413-2427.

Baek MS, Cho DS. 1996. An experimental study on the comparison of the establishment and growth of seedlings among three oak species. Korean J Ecol 19: 125-139.

Barbour MG, Burk JH, Pitts WD. 1987. Terrestrial Plant Ecology. 2nd ed. The Benjamin/Cummings Publishing Co., Inc., Menlo Park, CA.

Canham CD, Denslow JS, Platt WJ, Runkle JR, Spies TA, White PS. 1990. Light regimes beneath closed canopies and tree-fall gaps in temperate and tropical forests. Can J For Res 20: 620-631.

Chung TH, Lee WC. 1965. A study of the Korean woody plant zone and favorable region for the growth and proper species. Thesis Collect Sungkyunkwan Univ 10: 329-435.

Cody ML, Mooney HA. 1978. Convergence versus nonconvergence in Mediterranean-climate ecosytems. Annu Rev Ecol Syst 9: 265-321.

Diamond JM. 1978. Niche shifts and the rediscovery of interspecific competition. Am Sci 66: 322-331.

Elton CS. 1927. Animal Ecology. Sidgwick and Jackson, London.

Gaudio N, Balandier P, Philippe G, Dumas Y, Jean F, Ginisty C. 2011. Light-mediated influence of three understorey species (Calluna vulgaris, Pteridium aquilinum, Molinia caerulea) on the growth of Pinus sylvestris seedlings. Eur J For Res 130: 77-89.

Grime JP. 1979. Plant Strategies and Vegetation Processes. John Wiley \& Sons, New York.

Grime JP, Hodgson JG, Hunt R. 1998. Comparative Plant Ecology: A Functional Approach to Common British Species. Unwin Hyman, London.

Grime JP, Jeffrey DW. 1965. Seedling establishment in vertical gradients of sunlight. J Ecol 53: 621-642.

Grinnell J. 1917. The niche relationships of the California thrasher. Auk 34: 427-433.

Ha SH. 1989. Performance and photosynthesis of seedlings of several Quercus plants grown under the different light intensities. MS Thesis. Seoul National University. Seoul, Korea.

Han SJ, Kim HJ, You YH. 2009. Selection on tolerant oak species to water flooding for flood plain restoration. J Wetl Res 11: 1-7.

Hanski I. 1978. Some comments on the measurement of niche metrics. Ecology 59: 168-174.

Hong SK, Nakagoshi N. 1998. Comparison of the initial demographies of pine and oak populations in rural pine forests in Korea and Japan. J Plant Biol 41: 208-218. 
Hulbert SH. 1978. The measurement of niche overlap and some relatives. Ecology 59: 67-77.

Hutchinson GE. 1957. Concluding remarks. Cold Spring Harb Symp Quant Biol 22: 415-427.

Jensen AM, Gardiner ES, Vaughn KC. 2012. High-light acclimation in Quercus robur L. seedlings upon over-topping a shaded environment. Environ Exp Bot 78: 25-32.

Kim HJ, Shin BK, You YH, Kim CH. 2008a. A study on the vegetation of the present-day potential natural state of water for flood plain restoration in South Korea. Korean J Environ Ecol 22: 564-594.

Kim HR, Jeong HM, Kim HJ, You YH. 2008b. Ecological Niche of Quercus acutissima and Quercus variabilis. Korean J Environ Biol 26: 385-391.

Kim JU, Kil BS. 2000. The Mongolian Oak Forest in Korea. Wonkwang National University Press, Iksan.

Kim JW, Kim JH. 1994. Stomatal control and strategy segregation to drought stress in young trees of several oak species. Korean J Ecol 17: 241-249.

Kim JW, Lee YK. 2006. Classification and Assessment of Plant Communities. Worldscience, Seoul.

Kim YS, Ko SC, Oh BU. 1981. Distribution Atlas of Plants of Korea-Atlas of Fagaceae. Korea University Press, Seoul.

Korea Forest Research Institute. 1989. Chapter 4: Propagation and establishment of oak species. In: Studies on the development and utilization of Korean oak resources (II) (Cho JM, ed). Ministry of Science and Technology, Seoul, pp 141-210.

Lee HJ, You YH. 2009. Ecological Niche Breadth of Q. mongolica and overlap with Q. acutissima and Q. variabilis along with three environment gradients. Korean J Environ Biol 27: 191-197.

Lee HS, Bazzaz FA. 1985. Within and between species ecological variation in Polygonum pensylvanicum and Polygonum virginianum. J Seowon Thesis Collect 15: 273291.

Lee MJ. 2007. Community structure analysis and ecological planting model subject of the principal Quercus community in Korea. PhD Dissertation. Chungnam National University, Daejeon, Korea.

Levins R. 1968. Evolution in Changing Environments. Prinston University Press, Prinston, NJ.

Lim H, Kim HR, You YH. 2012. Growth difference between the seedlings of Quercus serrata and Q. aliena under light, moisture and nutrient gradients. J Wetl Res 14: 237-242.

Mandaák B, Pyšek P. 2001. The effects of light quality, nitrate concentration and presence of bracteoles on germination of different fruit types in the heterocarpous Atriplex sagittata. J Ecol 89: 149-158.

Noh HJ, Jeong HY. 2002. Understanding of Statistical Analysis by STATISTICA. Hyungseul Press, Seoul.

Odum EP. 1969. The strategy of ecosystem development. Science 164: 262-270.

Oh KK, Lee KJ. 1986. Phytosociological studies on natural vegetation in Hoo-Won, Changduk Palace. J Korean Inst Landsc Archit 14: 27-42.

Paine TD, Birch MC, Švihra. 1981. Niche breadth and resource partitioning by four sympatric species of bark beetles (Coleoptera: Scolytidae). Oecologia 48: 1-6.

Park HJ. 1984. Studies on the distribution and ecological characteristics of the major Quercus spp. in the middle temperate zone in Korea. MS Thesis. Chungnam National University, Daejeon, Korea.

Pianka ER. 1983. Evolutionary Ecology. 3rd ed. Harper \& Row, New York.

Polechová J, Storch D. 2008. Ecological niche. In: Evolutionary Ecology. Encyclopedia of Ecology. Vol. 2 (Jørgensen SE, Fath BD, eds). Elsevier, Oxford, pp 1088-1097.

Schoener TW. 1970. Nonsynchronous spatial overlap of lizards in patchy habitats. Ecology 51: 408-418.

Sim JS, Han SS. 2003. Ecophysiological characteristics of deciduous oak species (3): photosynthetic responses of leaves to change of light intensity. J Korean For 92: 208214.

Song MS. 2007. Analysis of distribution and association structure on the Sawtooth oak (Quercus acutissima) forest in Korea. PhD Dissertation. Changwon National University, Changwon, Korea.

Walter H. 1985. Vegetation of the Earth and Ecological Systems of the Geo-biosphere, 3rd ed. Springer-Verlag, New York.

Yang KC. 2001. Classification of major habitats based on the climatic conditions and topographic features in Korea. MS Thesis. Chungang University, Seoul, Korea.

Yanhong T, Hiroshi K, Mitsumasa S, Izumi W. 1994. Characteristics of transient photosynthesis in Quercus serrata seedlings grown under lightfleck and constant light regimes. Oecologia 100: 463-469.

Yim YJ, Baek SD. 1985. The Vegaetation of Mt. Seolag. Chungang University Press, Seoul.

Yimin L, Xihao S, Chongying G. 2006. Niche width and niche overlap: a method based on type-2 fuzzy sets. Ecol Res 21: 713-722.

You YH, Gi KJ, Han DU, Kwak YS, Kim JH. 1995. Succession and heterogeneity of plant community in Mt. Yongam, Kwangnung experimental forest. Korean J Ecol 18: 8997. 